\title{
Integrated Medical Curriculum: need of introducing clinical medicine in the first year of teaching
}

\author{
Vasantha Devasiri ${ }^{1}$, Champica Bodinayake ${ }^{2}$ \\ ${ }^{1}$ Senior Lecturer in Paediatrics, Head Medical education and StaffDevelopment Unit, \\ Senior Lecturer in Medicine, Person in Charge of the Foundation Module, Faculty of Medicine, \\ University of Ruhuna, Galle.
}

Throughout the world the undergraduate medical curricula are constantly being revised. This has become a necessity for survival of the medical schools as the expectations on the quality of the graduates are ever increasing.

The General Medical Council of UK (GMC) expects very high quality from the medical practitioners as it is stated in the document 'Good Medical Practice 2006.' It states "Patients need good doctors. Good doctors make the care of the patients their first concern: they are competent, keep their knowledge and skills up to date, establish and maintain good relationships with patients and colleagues, are honest and trustworthy, and act with integrity" [1]. This statement clearly shows high standards of expectations. The medical education should be revolutionized to achieve these goals. The GMC recommended that basic scientists and clinicians would have to get together and integrate their teaching, eliminating the pre-clinical and clinical divide. It also suggests that the examinations would also have to change, warns the GMC, as they "currently put a premium on the acquisition of facts at the expense of reasoning" [2].

Benchmark statement for medical graduates of Sri Lanka identifies professional values, attitudes, behaviour and ethics, scientific foundation of medicine, communication skills, clinical skills, population health and health systems, management of information as the key areas a medical graduate should develop his or her knowledge and skills [3]. The diversity of relevant areas covered in this document demands the medical educators to change the approach as all the aspects mentioned in the bench mark document are not consciously addressed in existing traditional curricula.
The medical faculties in Sri Lanka have already started adopting new curricula to face the new challenges of education. Medical faculties in Colombo, Peradeniya and Kelaniya Universities have already given up the traditional curricula to adopt a modular system either of problem based or system based.

The medical faculty of the University of Ruhuna is also in the process of changing its traditional curriculum. Surveys conducted by the Medical Education and the Staff Development Unit among the academic members of the extended faculty and the recent graduates of the faculty, show that all of them agree that a more extensive integration is needed in the curriculum.

The curriculum could be defined as made up of all the experiences learners have that enable them to reach their intended achievements from the course [4]. A curriculum should be enriched with teaching learning experiences which should be powerful enough to produce desired learning outcomes.

It is important to understand that the education is not mere acquisition of information. It is a way of interacting with the world, which should bring out the desired change in the learned person. Mere acquisition of information will not bring the expected change but the way we structure that information and think with it does will make the necessary conceptual change in the learner [5].

As the expectations of the public on the quality of the doctors are ever increasing, the medical schools face a formidable challenge to review the curriculum and make necessary changes to meet these demands. Integration of curriculum played a major role in these changes since it was fist tried in Case Western Reserve Medical School in Cleveland, Ohio in 1952. Since then, lot of 
changes have taken place with a move from the traditional curriculum towards system based integration and to problem based curricula.

In the process of integration, it is important to think about all the aspects identified in the subject bench mark document. It is not just integration of basic sciences and clinical skills as it thought to be. The integration could be more clearly and broadly defined as the integration of component parts of science and clinical experience, knowledge, skills and attitudes, judgment and problem solving and even of continuing to learn through reflection on practice [6]. Above statement clearly shows the importance of introducing clinical practice at a very early stage in the carrier. It is beneficial as everything students learn could be related to the clinical practice. This will facilitate the process of student learning as it will show them the appropriateness of what they are learning and it's relevance to the learning outcomes. Most of the theories of learning support this type of approach.

It is difficult to discuss extensively about learning theories in an article like this. Our idea is to introduce few of the well known learning theories to show the importance of early integration and its impact on the system.

Knowles' theory of andragogy is an attempt to develop a theory specifically for adult learning. Knowles emphasizes that adults are self-directed learners and expected to take responsibility for decisions. Andragogy assumes that the adults need to know why they need to learn something, and they learn by experiencing. Adults' approach to learning is as problem-solving and adults learn best when they see the immediate value of what they learn. In practical terms, andragogy means that instruction for adults needs to focus more on the process and less on the content being taught. Strategies such as case studies, role playing, simulations, and self-evaluation are most useful [7].

It shows that adults prefer to learn what is relevant to them on their own; hence, the early experiences with clinical medicine will be beneficial. Other educational theories among many which support the fact that early integration is required are the theories of constructivism and situated learning.

In the theory of constructivism, learners construct their understanding of the world through their interaction with it and that the learning can occur when new experiences of the world fit into learners existing cognitive structures. New learning experiences should be modified to fit into the existing cognitive structure [8]. The guiding principles in constructivism include that the learning is a search for meaning. Therefore, learning must start with the issues around which students are actively trying to construct meaning and the meaning requires understanding wholes as well as parts, and parts must be understood in the context of wholes. Therefore, the learning process focuses on primary concepts and not on isolated facts [9].

Introduction of clinical medicine in the preclinical period should be done in a graded way to fit into the cognitive development of the students for them to assimilate new knowledge. It will help them to understand pre-clinical subjects as a part of the whole. This will give a meaning to education and will enhance learning. This will create a situation where learning will become an activity in which they are involved.

In the theory of situated learning, J. Lave argues that learning as it normally occurs is a function of the activity, context and culture in which it occurs. ${ }^{10}$ The principle of using situated learning theory is knowledge needs to be presented in an authentic context, i.e., settings and applications that would normally involve that knowledge and the learning requires social interaction and collaboration [10]. Most of the other learning theories as well support the case of early introduction of clinical skills. It has shown in studies that early introduction of clinical medicine enhances the students learning interest and made them feel like doctors [11].

It must be appreciated that the first year is the hardest period for students as during this period they will have to learn a whole lot of new concepts in new fields. This will become more difficult for them if they can't appreciate the relevance and importance of what they are 
learning. They will need constant explanation on why they should learn all these [12]. Through introduction of clinical medicine in the first year they will understand the relevance of basic concepts of Physiology, Biochemistry and Anatomy making it a meaningful learning experience.

It is important to pay a meticulous attention on the teaching learning methods in which the clinical medicine is introduced to the first year students. Mere supplementation of an anatomy or a physiology lecture with a demonstration of a patient will not be enough to bring out the desired outcomes of integration. The teaching learning activities should really integrate component parts of science and clinical experience, knowledge, skills and attitudes, judgment and problem solving and reflection on practice. To achieve this all sorts of active teaching learning strategies such as small group discussions, debates, role play, authentic projects, small scale research and attending to patients have to be incorporated into the first year teaching. This will help to change the learning styles of the students by encouraging active participation and will help to achieve some of the goals mentioned in the bench mark statement.

In a recent visit authors have personally experienced how the clinical medicine is successfully incorporated in to phase 1 medical curriculum as a case led framework in Durham University, UK. The students start the course with a foundation case through which they learn molecular and cellular basis of the disease, how it affects the physiological functions within the body and its effects on the individual, family and the society. This will lead to more case led study of other selected important topics. In addition, there are projects in which they are allocated to families where there is a patient with a chronic illness. They have several lecture demonstrations in which they get opportunity to interview patients and visits to the hospital with very clear learning objectives, during which they are guided by the senior students. The objectives of the lectures are directly related to the clinical practice.

The medical faculty of the University of Ruhuna has already introduced the foundation module which covers areas such as communication skills, medical ethics, humanities and IT skills. Through the foundation module, students are exposed to a whole lot of new teaching learning methods. There are lots of group activities, projects, presentations and interviews through which students have opportunities to develop their learning skills which enhance active learning. This will provide a good foundation to introduce active learning methods which are properly integrated with clinical medicine fairly early in the training program. This will definitely make the students better learners as this approach will make learning a more meaningful experience.

The authors believe that the existing curriculum could be improved remarkably by introducing new teaching learning sessions related to clinical practice of medicine. At least in the initial stages, certain percentage of teaching learning activities could be properly integrated. In the meantime, the assessment methods should also be changed accordingly. Further steps towards more extensive integration could be taken depending on the feedback. This is an essential step in developing a quality medical graduate.

\section{References}

1. http://gmcuk.org/guidance/good_medical_practice/ index. asp6/26/2007

2. L Dillner GMC says it will watch curriculum reforms. News BMJ 1994;308:361

3. Subject bench mark statement Medicine: February 2004.

4. Janet Grant; Principles of curriculum design; ASME 2006

5. John Biggs; Teaching for quality learning at University Buckingham. Open University Press.

6. Janet Grant, Principles of curriculum design; ASME 2006

7. http://tip.psychology.org/knowles.html 6/16/2007

8. Driver R; Making sense of secondary education into children's ideas: Roultedge:1994

9. http://www.funderstanding.com/constructivism.cfm 6/16/2007

10. http://tip.psychology.org/lave.html 6/16/2007

11. Lam TP, Irwin M, Chow LW, Chan P. Early introduction of clinical skills teaching in a medical curriculum--factors affecting students' learning. Med Educ 2002 Mar; 36(3):233-40.)

12. http://www.flinders.edu.au/teach/t41/teaching/ firstindex.php 